\title{
CRESCIMENTO DE Ruta graveolens L. INOCULADA COM MICORRIZAS SOB DOSES DE FÓSFORO
}

Rayane Monique Sete da Cruz ${ }^{1}$ Bianca de Almeida Marchi Bruna Caroline de Souza Jean Silva de Souza Sonivaldo Ruzzene Beltrame ${ }^{1,2}$ Odair Alberton ${ }^{3}$

CRUZ, R. M. S. da; MARCHI, B. de A.; SOUZA, B. C. de; SOUZA, J. S. de; BELTRAME, S. R.; ALBERTON, O. Crescimento de Ruta graveolens L. inoculada com micorrizas sob doses de fósforo. Arq. Ciênc. Vet. Zool. UNIPAR, Umuarama, v. 20, n. 1, p. 23-27, jan./mar. 2017.

RESUMO: Os fungos micorrízicos arbusculares (FMAs) são micro-organismos que fazem simbiose com raízes da maioria das plantas. O objetivo deste trabalho foi avaliar a influência dos FMAs Rhizophagus clarus e Claroideoglomus etunicatum em substrato sob baixa e ou alta dose de fósforo (P), na produção de biomassa e na acumulação de P na arruda (Ruta graveolens L.). O experimento foi conduzido no laboratório de botânica da Universidade Paranaense - UNIPAR, município de Umuarama - PR. O delineamento experimental foi inteiramente ao acaso, em fatorial 3x2, sendo os fatores: FMAs (sem FMA, com $R$. clarus e ou com $C$. etunicatum); duas doses de $\mathrm{P}\left(20\right.$ e $\left.200 \mathrm{mg} \mathrm{kg}^{-1}\right)$ com 8 repetições por tratamento, num total de 48 unidades experimentais (vasos de $3 \mathrm{~L}$ ). Avaliou-se a produção de massa seca das raízes (MSR), massa seca da parte aérea (MSPA), massa seca total (MST) e o acúmulo de P na parte aérea da planta (PPA). A produção de MSR, MSPA e MST pela planta não foram significativamente afetadas apenas pela adição de $\mathrm{P}$ ao substrato, porém sim, pela inoculação com o FMA C. etunicatum, sob baixo e ou alto P. O acúmulo de P na parte aérea da planta foi aumentado significativamente no tratamento sem a inoculação com FMAs. Conclui-se que a inoculação com C. etunicatum é indicada para aumentar a produtividade da arruda.

PALAVRAS-CHAVE: Agricultura ecológica. Plantas condimentares e medicinais. Simbiose.

\section{GROWTH OF Ruta graveolens L. INOCULATED WITH ARBUSCULAR MYCORRHIZAL FUNGI UNDER LEVELS OF PHOSPHORUS}

ABSTRACT: Arbuscular mycorrhizal fungi (AMF) are microorganisms that present symbiosis with the roots of most plants. The purpose of this work was to evaluate the influence of AMF Rhizophagus clarus and Claroideoglomus etunicatum on low and high doses of phosphorus (P) on plant biomass and $\mathrm{P}$ accumulation in rue (Ruta graveolens $\mathrm{L}$.). The experiment was performed in the botanical laboratory at Universidade Paranaense - UNIPAR in the city of Umuarama, in the state of Paraná, Brazil. It used a completely randomized 3x2 experimental design, being: AMFs (without AMF, with $R$. clarus and/or with $C$. etunicatum); two levels of $\mathrm{P}\left(20\right.$ and $\left.200 \mathrm{mg} \mathrm{kg}^{-1}\right)$ with 8 repetitions per treatment, totaling 48 experimental units (3 L pots). Root dry matter (RDM), shoot dry matter (SDM), total dry matter (TDM) and P accumulation in the aerial part of the plant were evaluated. The production of RDM, SDM and TDM by the plant was not significantly affected by the addition of P to the substrate, but by the inoculation with AMF $C$. etunicatum under low and/or high $\mathrm{P}$. The accumulation of $\mathrm{P}$ in the aerial part of the plant significantly increased in the treatment without AMF inoculation. It was concluded that inoculation with $C$. etunicatum is indicated to increase the productivity of rue.

KEYWORDS: Eco-friendly agriculture. Spices and medicinal plants. Symbiosis.

\section{CRECIMIENTO DEL Ruta graveolens L. INOCULADA CON MICORRIZAS BAJO DOSIS DE FÓSFORO}

RESUMEN: Los hongos micorrícicos arbusculares (HMA) son microorganismos que forman simbiosis con las raíces de la mayoría de las plantas. El objetivo de este estudio fue evaluar la influencia del HMA Rhizophagus clarus y Claroideoglomus etunicatum en substrato so baja y/o alta dosis de fósforo $(\mathrm{P})$, en la producción de biomasa y en la acumulación de $\mathrm{P}$ en la ruda (Ruta graveolens L.). El experimento se llevó a cabo en el laboratorio de botánica de la Universidad Paranaense - Unipar, municipio de Umuarama - PR. El diseño experimental fue completamente al azar, en un 3x2 factorial, con los factores: HMA (Sin HMA, con R. clarus y C. etunicatum); dos dosis de P $\left(20\right.$ y $\left.200 \mathrm{mg} \mathrm{kg}^{-1}\right)$ con 8 repeticiones por tratamiento de un total de 48 unidades experimentales (vasos de 3 L). Se evaluó la producción de materia seca de las raíces (MSR), materia seca de la parte aérea (MSPA), materia seca total (MST) y la acumulación de P en la parte aérea de la planta (PPA). La producción de MSR, MSPA y MST por la planta no se vieron afectados significativamente sólo mediante la adición de P al sustrato, sino por

DOI: https://doi.org/10.25110/arqvet.v20i1.2017.6316

Discentes da Universidade Paranaense - UNIPAR, Umuarama - PR.

${ }^{2}$ Docente do Instituto Federal de Educação, Ciência e Tecnologia de Mato Grosso do Sul - IFMS, Dourados - MS.

${ }^{3}$ Docente do Programa de Pós-graduação em Biotecnologia Aplicada à Agricultura da UNIPAR. Umuarama - PR. E-mail: odair@prof.unipar.br 
inoculación con HMA C. etunicatum so bajo y/o alto P. El acúmulo de P en parte aérea de la planta se incrementó significativamente en el tratamiento sin inoculación con HMA. Se concluye que la inoculación con C. etunicatum está indicada para aumentar la productividad de la ruda.

PALABRAS CLAVE: Agricultura ecológica. Plantas culinarias y medicinales. Simbiosis.

\section{Introdução}

A espécie Ruta graveolens L é uma planta de origem francesa, pertencente à família das Rutaceas, conhecida popularmente como arruda, pode apresentar diversas atividades, entres elas: analgésica, anti-hemorrágica, anti-inflamatória, calmante, estimulante, repelente, vermicida, entre outras. Por conta de suas propriedades medicinais, muitos estudos envolvendo esta espécie vêm sendo conduzidos nos últimos anos (MEJRI et al., 2010; KHALID, 2014; ORLANDA; NASCIMENTO, 2015).

A arruda tem sido largamente utilizada como recurso medicinal, o que provocou a implementação de diversas técnicas de cultivo, como a introdução de populações de fungos microrrizicos arbusculares (FMAs) para um aumento de produtividade, onde a efetividade micorrízica é geralmente estudada em termos de crescimento e absorção de nutrientes, em relação à planta não micorrizada, com variações de acordo com a espécie hospedeira e o FMA utilizado. Plantas micorrizadas podem aumentar a absorção de fósforo $(\mathrm{P})$, melhorando o desenvolvimento das mesmas, aumentando a resistência aos estresses bióticos e abióticos e produzindo a maior quantidade possível de fitomassa ou de substâncias com atividade medicinal e ou aromática inerente a cada espécie, sem a necessidade de suplementação de insumos agrícolas e agroquímicos (RUSSOMANNO et al., 2010; MALIK et al., 2012; LERMEN et al., 2015; URCOVICHE et al., 2015).

A partir da colonização do ambiente terrestre, as plantas desenvolveram estratégias para enfrentar estresses bióticos e abióticos em consequência do ciclo de vida sedentário que possuem. As micorrizas podem ser consideradas uma das mais bem sucedidas estratégias de bioproteção, tanto para a planta quanto para o próprio fungo (GIANINAZZI-PEARSON, 1996; PARKASH et al., 2011).

O P é o macronutriente primário do solo com uma das menores taxas de absorção, se comparado com os demais. Sua ação no metabolismo da planta o torna indispensável para o crescimento e produção vegetal, interferindo nos processos de fotossíntese, respiração, armazenamento e transferência de energia, divisão celular e crescimento das células. Contribui ainda para o crescimento prematuro das raízes, qualidade de frutas, verduras, grãos e formação das sementes (TAIZ; ZEIGER, 2013). Por interferir em processos vitais para as plantas, é essencial que se faça seu suprimento de maneira adequada desde a germinação, principalmente em plantas de ciclo curto (MARSCHNER, 2012).

Nas regiões tropicais, que tradicionalmente apresentam solos com níveis baixos de $\mathrm{P}$, as associações micorrízicas merecem mais atenção considerando o ponto de vista econômico, pois podem minimizar os gastos com insumos, tais como fertilizantes minerais, irrigação e pesticidas (SIEVERDING, 2006), já que a simbiose micorrízica constitui um mecanismo adaptativo que permite maximizar a aquisição de $\mathrm{P}$ de uma forma que dispende menos energia que a própria produção de raízes (CLARK et al., 2000).

Diante desse contexto, este trabalho teve como ob- jetivo estudar a influência da inoculação dos FMAs Rhizophagus clarus e ou Claroideoglomus etunicatum no crescimento da arruda cultivada em diferentes doses de fósforo.

\section{Material e Métodos}

O experimento teve duração de 3 meses e foi realizado no laboratório de botânica da Universidade Paranaense - UNIPAR, Umuarama/PR, utilizando-se substrato preparado com areia e vermiculita (1:1, vol.: vol.), que foi colocado dentro de sacos plásticos preto e fumigado com 10 $\mathrm{mL}$ de clorofórmio $\left(\mathrm{CHCl}_{3}\right) \mathrm{Kg}^{-1}$ de solo (ENDLEWEBER; SCHEU, 2006); após misturado o clorofórmio ao solo, os sacos foram hermeticamente fechados e deixados fumigando por 3 dias. Após esse período, foram abertos dentro de uma câmera de exaustão química e esperado uma semana para iniciar o experimento.

Foram montados 48 vasos de polietileno com $3 \mathrm{~kg}$ de substrato previamente fumigado.

Em cada vaso foram plantadas 10 sementes de arruda (Procedência - Feltrin sementes) e 200 esporos dos FMAs Rhizophagus clarus (syn. Glomus clarum) e ou Claroideoglomus etunicatum (syn. Glomus etunicatum) provenientes do banco de Glomales da UNIPAR nos tratamentos com inoculação (URCOVICHE et al., 2015). Nos tratamentos não inoculados (controles) foram adicionados $100 \mathrm{~mL}$ do filtrado do solo inóculo (100 g do solo inóculo $\mathrm{L}^{-1}$ de água deionizada estéril). Desse modo temos apenas o efeito dos FMAs adicionados.

Os tratamentos foram:

Tratamento 1: preparado de substrato $+20 \mathrm{mg} \mathrm{P} \mathrm{Kg}^{-1}$

Tratamento 2: preparado de substrato $+200 \mathrm{mg} \mathrm{P} \mathrm{Kg}^{-1}$

Tratamento 3: preparado de substrato $+R$. clarus $+20 \mathrm{mg} \mathrm{P}$ $\mathrm{Kg}^{-1}$

Tratamento 4: preparado de substrato $+R$. clarus $+200 \mathrm{mg}$ $\mathrm{P} \mathrm{Kg}^{-1}$

Tratamento 5: preparado de substrato + C. etunicatum +20 mg P Kg ${ }^{-1}$

Tratamento 6: preparado de substrato + C. etunicatum +200 mg P Kg-1

Todos os tratamentos foram irrigados a cada 2 dias com meia concentração de Hoagland e Arnon (1950) solução, exceto para o $\mathrm{P}$ adicionado já no início do experimento conforme Urcoviche et al. (2015)

No final do período experimental as plantas foram secas em estufa $\left(65^{\circ} \mathrm{C}\right)$, até atingirem massa constante, obtendo a massa seca da parte aérea (MSPA), a massa seca das raízes (MSR) e massa seca total (MST) através da pesagem com balança digital.

Para a determinação do $\mathrm{P}$ do tecido vegetal, foram pesados $0,5 \mathrm{~g}$ das folhas secas em estufa $\left(65^{\circ} \mathrm{C}\right.$ por $\left.48 \mathrm{~h}\right)$ e moída em cadinhos. Em seguida, as amostras foram colocadas em mufla para incineração a $500{ }^{\circ} \mathrm{C}$ por 3,5 horas. Depois de esfriar, foram adicionados $10 \mathrm{~mL}$ de $\mathrm{HCl} 1 \mathrm{~mol} \mathrm{~L}^{-1}$ e posicionam-se os cadinhos em chapa aquecida sob exaustor, a $70-80{ }^{\circ} \mathrm{C}$ por $10 \mathrm{~min}$, para a solubilização total dos 
elementos. Na sequência, conforme Silva (2009), o P foi estimado por colorimetria com molibdato de amônio + ácido ascórbico em espectrofotômetro usando filtro vermelho e comprimento de onda de $660 \mathrm{~nm}$.

O delineamento experimental utilizado foi inteiramente casualizado com 8 repetições em um em fatorial $3 \times 2$, sendo os fatores: FMAs (sem FMA, com $R$. clarus e ou com C. etunicatum); duas doses de P (20 e $\left.200 \mathrm{mg} \mathrm{kg}^{-1}\right)$. Os dados foram submetidos à análise de variância (ANOVA). As médias foram comparadas por meio do teste de Duncan $(\mathrm{p} \leq 0,05)$ utilizando o programa estatístico SPSS versão 22.0 para Windows (SPSS Inc., Chicago, IL, USA).

\section{Resultados e Discussão}

A produção de massa seca das raízes (MSR) e de massa seca da parte aérea (MSPA) não foi afetada $(p \leq 0,05)$ pela adição de 20 ou de $200 \mathrm{mg} \mathrm{kg}^{-1}$ de fósforo (P). Para 20 $\mathrm{mg} \mathrm{kg}^{-1}$ de P, a MSR e MSPA foi de 1,00 e 6,96 g vaso $^{-1}$, respectivamente (Tabela 1). Para a adição de 10 (dez) vezes essa quantidade de $\mathrm{P}$ (200 mg kg-1), a produção média de MSR foi de 1,26 $\mathrm{g}$ e a de MSPA foi de 7,30 $\mathrm{g}$. Esses resultados são semelhantes aos obtidos no cultivo de Mentha Piperita L sob diferentes dosagens de fósforo $(\mathrm{P})$, realizado também em casa de vegetação, onde verificou-se que a adição de 60, 120 ou $180 \mathrm{~kg} \mathrm{ha}^{-1}$ de $\mathrm{P}_{2} \mathrm{O}_{5}$ não afetou estatisticamente a produção de MSR nem de MSPA da cultivar (SOUZA et al., 2013).

Parkash et al. (2011), estudaram a arruda inoculada com três espécies de FMAs e observaram significante aumento na produção de biomassa da planta inoculada em relação ao controle não inoculado. Este resultado corrobora com os observados no presente estudo, no qual a MSPA e MST foram aumentadas significantemente na planta inoculada (Tabela 1).

Tabela 1: Produção de massa seca das raízes (MSR), massa seca da parte aérea (MSPA), massa seca total (MST) e teor de fósforo na parte aérea $(\mathrm{P})$ de Ruta graveolens L. inoculada com micorrizas na presença de diferentes concentrações de fósforo (P).

\begin{tabular}{|c|c|c|c|c|}
\hline \multirow{2}{*}{ Tratamento } & MSR & MSPA & MST & $\mathbf{P}$ \\
\hline & \multicolumn{3}{|c|}{ massa seca produzida (g vaso- 1 ) } & (mg g-1) \\
\hline \multicolumn{5}{|l|}{$\mathrm{P}$ adicionado (mg kg-1 de substrato) } \\
\hline $20 \mathrm{P}=20$ & $1,00 \pm 0,16 \mathrm{a}$ & $6,96 \pm 0,57 \mathrm{a}$ & $7,96 \pm 0,70 \mathrm{a}$ & $2,52 \pm 0,12 \mathrm{~b}$ \\
\hline $200 \mathrm{P}=200$ & $1,26 \pm 0,81 \mathrm{a}$ & $7,30 \pm 0,47 \mathrm{a}$ & $8,55 \pm 0,60 \mathrm{a}$ & $3,58 \pm 0,22 \mathrm{a}$ \\
\hline Valor de $p$ & 0,288 & 0,653 & 0,525 & $<0,001$ \\
\hline \multicolumn{5}{|l|}{ FMA } \\
\hline Controle sem micorriza (cont.) & $0,52 \pm 0,03 \mathrm{~b}$ & $4,24 \pm 0,22 \mathrm{c}$ & $4,76 \pm 0,22 \mathrm{c}$ & $3,41 \pm 0,41 \mathrm{a}$ \\
\hline Rhizophagus clarus (Rc) & $0,84 \pm 0,07 \mathrm{~b}$ & $7,87 \pm 0,44 \mathrm{~b}$ & $8,71 \pm 0,49 b$ & $2,81 \pm 0,13 \mathrm{a}$ \\
\hline Claroideoglomus etunicatum $(\mathrm{Ce})$ & $2,03 \pm 0,21 \mathrm{a}$ & $9,27 \pm 0,37 \mathrm{a}$ & $11,30 \pm 0,51 \mathrm{a}$ & $2,92 \pm 0,23 \mathrm{a}$ \\
\hline Valor de $p$ & $<0,001$ & $<0,001$ & $<0,001$ & 0,290 \\
\hline \multicolumn{5}{|l|}{ P X FMA } \\
\hline $20 \mathrm{P} \times$ cont. & $0,61 \pm 0,04 \mathrm{c}$ & $4,06 \pm 0,14 \mathrm{c}$ & $4,67 \pm 0,14 \mathrm{~d}$ & $2,43 \pm 0,19 \mathrm{c}$ \\
\hline 200P x cont. & $0,43 \pm 0,02 \mathrm{c}$ & $4,43 \pm 0,42 \mathrm{c}$ & $4,86 \pm 0,43 \mathrm{~d}$ & $4,39 \pm 0,31 \mathrm{a}$ \\
\hline $20 \mathrm{P} \times \mathrm{Rc}$ & $0,72 \pm 0,09 \mathrm{c}$ & $7,08 \pm 0,65 \mathrm{~b}$ & $7,80 \pm 0,74 \mathrm{c}$ & $2,57 \pm 0,29 \mathrm{bc}$ \\
\hline 200P x Rc & $0,96 \pm 0,08 \mathrm{c}$ & $8,66 \pm 0,48 \mathrm{a}$ & $9,62 \pm 0,50 \mathrm{~b}$ & $3,27 \pm 0,28 \mathrm{bc}$ \\
\hline $20 \mathrm{P} \times \mathrm{Ce}$ & $1,67 \pm 0,36 b$ & $9,74 \pm 0,67 \mathrm{a}$ & $11,41 \pm 1,01 \mathrm{a}$ & $2,55 \pm 0,17 \mathrm{bc}$ \\
\hline 200P x Ce & $2,38 \pm 0,16 \mathrm{a}$ & $8,80 \pm 0,30 \mathrm{a}$ & $11,18 \pm 0,27 \mathrm{ab}$ & $3,07 \pm 0,05 \mathrm{bc}$ \\
\hline Valor de $p$ & $<0,001$ & $<0,001$ & $<0,001$ & $<0,001$ \\
\hline
\end{tabular}

O tratamento controle, sem inoculação de micorrizas, apresentou os menores resultados para a média da produção de biomassa pela planta, produzindo a $0,52 \mathrm{~g}^{\text {vaso }^{-1}}$ de MSR, 4,24 g vaso-1 de MSPA e 4,76 g vaso-1 de MST. A inoculação tanto com $C$. etunicatum como com $R$. clarus aumentou significativamente $(p \leq 0,001)$ a produção de MSPA e MST de arruda. No entanto, os maiores valores foram obtidos com C. etunicatum e não com R. clarus (Tabela 1). Essa maior produção de biomassa das plantas inoculadas com primeiro FMA, em comparação com o segundo, pode ser explicada pela seletividade existente entre a planta hospedeira e determinadas espécies de FMAs. Essa eficiência se deve a características inerentes aos genótipos do fungo e da planta, e da interação destes, em simbiose, com o ambiente (SOARES et al., 2012). Os resultados obtidos com a inoculação de $C$. etunicatum neste estudo corroboram com os resultados obtidos com a inoculação deste fungo no crescimento de mudas de Medicago sativa L. (CARNEIRO et al., 2009), de Genipa americana L. (SOARES et al., 2012) e de Mimosa caesalpiniifolia B. (OLIVEIRA; ALIXANDRE, 2013), o que indica seu potencial como agente promotor do crescimento das plantas.

A adição de grande quantidade $\mathrm{P}$ no solo aumentou significativamente $(p \leq 0,01)$ a concentração desse elemento na parte aérea da planta, que passou de $2,52 \mathrm{mg} \mathrm{g}^{-1}$ quando adicionado $20 \mathrm{mg} \mathrm{kg}^{-1}$ para $3,58 \mathrm{mg} \mathrm{g}^{-1}$ quando adicionado $200 \mathrm{mg} \mathrm{kg}^{-1}$ de P no solo (Tabela 1). A inoculação de FMAs não afetou significativamente a concentração de $\mathrm{P}$ na parte 
aérea da planta, cujo maior valor foi $3,41 \mathrm{mg} \mathrm{g}^{-1}$, obtido no grupo controle. Resultados similares foram obtidos no cultivo de alface em canteiros protegidos e não climatizados, com presença e ausência de fósforo, onde a adição de $400 \mathrm{~kg} \mathrm{ha}^{-1}$ de $\mathrm{P}_{2} \mathrm{O}_{5}$ no solo resultou no aumento de mais de $80 \%$ da sua concentração na parte aérea da planta, em comparação com o grupo controle (QUADROS et al., 2011).

$\mathrm{A}$ adição de $\mathrm{P}$ associada à inoculação de FMAs aumentou $(p \leq 0,01)$ a produção de MSR, MSPA e MST da planta. No entanto, os maiores valores foram obtidos em plantas inoculadas com $C$. etunicatum. Este fungo foi também o único que aumentou a MSR, o que ocorreu no nível mais elevado de P no solo (Tabela 1). Resultados opostos foram obtidos em estudo similar, realizado em casa de vegetação, onde o cultivo de sabiá com adição de 60, 120 e 240 $\mathrm{mg}$ de $\mathrm{P} \mathrm{dm}^{-3}$ no solo inoculado com $C$. etunicatum resultou em um incremento de $564 \%$ na produção de massa seca total pela planta, na ausência de fertilização fosfatada (OLIVEIRA; ALIXANDRE, 2013). Isso pode ser explicado devido à diminuição da taxa de colonização pelo FMA na medida em que são elevados os níveis de $\mathrm{P}$ no solo pois, em níveis mais elevados de $\mathrm{P}$, verificou-se a redução de $0,26 \%$ na taxa de colonização micorrízica para cada $\mathrm{mg} \mathrm{P} \mathrm{dm}^{-3}$ de solo aplicados (OLIVEIRA; ALIXANDRE, 2013). A diminuição da colonização micorrízica afeta negativamente a simbiose entre a planta e o FMA e, consequentemente, ocorre menor produção de biomassa pela planta (SMITH; READ, 2008).

Entretanto, em estudos sobre o cultivo de café inoculado com $G$. clarum em solo com adição de $40 \mu \mathrm{g} \mathrm{g}^{-1}$ de $\mathrm{P}$, verificou-se o aumento de $20 \%$ da produção de matéria seca na comparação com o grupo controle (MIRANDA, 2008). Resultado semelhante foi obtido também no cultivo de sorgo inoculado com $G$. etunicatum em solo adubado com 100 e $200 \mathrm{~kg} \mathrm{ha}^{-1}$ de $\mathrm{P}_{2} \mathrm{O}_{5}$, onde verificou-se 131 e $212 \%$, respectivamente, de aumento da matéria seca produzida pela planta (MIRANDA, 2008). Os mecanismos que regulam a eficiência micorrízica no crescimento vegetal em solo com presença de $\mathrm{P}$ ainda não estão bem definidos, mas fatores como o aumento da lecitina nas raízes e a alteração da permeabilidade de suas membranas, reduzem a germinação e o crescimento do micélio, provocando a diminuição da colonização das mesmas.

Esses aspectos, aliados às especificidades inerentes à simbiose entre cada tipo de fungo, o solo e a planta, bem como a adição de P no solo, formam um conjunto de fatores que afetam o manejo dos FMAs, as condições de crescimento da planta, e ainda processos fisiológicos mais complexos, tais como a produção de exsudados que estimulam da taxa de colonização micorrízica, pela planta, em níveis mais baixos de P (NAGAHASHI; DOUDS, 2007).

Malik et al. (2012), estudaram a arruda inoculada com o FMA Glomus spp. na Índia, observaram aumento no acúmulo de biomassa de 33\%. Resultado similar foi observado no presente estudo, confirmando a importância de se inocular a arruda com FMA, levando a uma maior produção desta planta e de forma barata e sustentável.

\section{Conclusão}

A inoculação de arruda com os FMAs C. etunicatum e $R$. clarus aumenta sua produção de biomassa, independente da adição de P no solo. Inoculando o FMA $C$. etunicatum aumentou a produção de massa seca das raízes e da parte aérea da planta. Dessa forma, C. etunicatum é indicado para o aumento da produtividade de arruda.

\section{Agradecimentos}

Os autores agradecem a Universidade Paranaense UNIPAR pelo apoio à pesquisa. Sonivaldo Ruzzene Beltrame agrade ao IFMS pelo apoio à capacitação. Odair Alberton agradece a bolsa produtividade de pesquisa concebida pelo CNPq.

\section{Referências}

CARNEIRO, R. F. V. et al. Crescimento vegetativo e aquisição de nutrientes pela alfafa em resposta à micorríza e doses de fósforo. Revista Brasileira de Ciências Agrárias, Recife, v. 4, p. 267-273, 2009.

CLARK, R.B.; ZETO, S. K. Mineral acquisition by arbuscular mycorrhizal plants. Journal of Plant Nutrition, New York, v. 23, p. 867-902, 2000.

ENDLEWEBER, K., SCHEU, S. Establishing arbuscular mycorrhiza-free soil: A comparison of six methods and their effects on nutrient mobilization. Applied soil ecology: a section of Agriculture, Ecosystems \& Environment, Amsterdam, v. 34, p. 276-279, 2006.

GIANINAZZI-PEARSON, V. Plant cell responses to arbuscular mycorrhizal fungi: getting to the roots of the symbiosis. The Plant Cell, Rockville, v. 8, p. 1871-1883, 1996.

HOAGLAND, D. R.; ARNON, D. I. The water culture method for growing plants without soil. California Agricultural Experiment Station, San Francisco, v. 347. p. $1-32,1950$.

KHALID, K. A. influences of silicate dissolving bacteria and natural potassium on growth and essential oil of rue plant. Thai Journal of Agricultural Science, Bangkok, v. 47, p. 31-36, 2014

LERMEN, C. et al. Growth of Cymbopogon citratus inoculated with mycorrhizal fungi under different levels of lead. Scientia Horticulturae, Amsterdam, v. 186, p. 239246,2015

MALIK, A. A. et al. Effect of inorganic and biological fertilizer treatments on essential oil composition of Ruta graveolens L. Journal of Herbs, Spices \& Medicinal Plants, Binghamton, v. 18, p. 191-202, 2012

MARSCHNER, H. Mineral nutrition of higher plants. 3. ed London: Elsevier, 2012. 643p.

MEJRI, J. et al. Chemical composition of the essential oil of Ruta chalepensis L: Influence of drying, hydro-distillation duration and plant parts. Industrial Crops and Products, 
Amsterdam, v. 32 p. 671-673, 2010.

MIRANDA, J. C. C. Cerrado - micorriza arbuscular: ocorrência e manejo. Planaltina/DF: Embrapa Cerrados, 2008 .

NAGAHASHI, G.; DOUDS, D. J. Separated components of root exudate and cytosol stimulate different morphologically identifiable types of branching responses by arbuscular mycorrhizal fungi. Mycological research, Cambridge, v. 111, p. 487-492, 2007.

OLIVEIRA, J. J. F.; ALIXANDRE, T. F. Parâmetros biométricos de mudas de sabiá micorrizadas sob níveis de fósforo em Latossolo Amarelo. Pesquisa florestal brasileira, Colombo, v. 33, p. 159-167, 2013.

ORLANDA, J. F. F.; NASCIMENTO, A. R. Chemical composition and antibacterial activity of Ruta graveolens $\mathrm{L}$. (Rutaceae) volatile oils, from São Luís, Maranhão, Brazil. South African Journal of Botany, Pretoria, v. 99, p. 103$106,2015$.

PARKASH, V. et al. Rhizospheric effect of vesicular arbuscular mycorrhizal inoculation on biomass production of Ruta graveolens L.: a potential medicinal and aromatic herb. Journal of Plant Nutrition, New York, v. 34, p. 1386-1396, 2011

QUADROS, B. R. et al. Teor de macronutrientes na parte aérea e sementes de plantas de alface em função de doses de composto orgânico com e sem adição de fósforo ao solo. Semina: Ciências Agrárias, Londrina, v. 32, p. 1725-1734, 2011 .

RUSSOMANNO, O. M. R. et al. Influência de fungos microrrízicos arbusculares no desenvolvimento de plantas de alecrim e manjericão. Arquivos do Instituto Biológico, São Paulo, v.75, p. 37-43, 2008.

SIEVERDING, E.; OEHL, F. Revision of Entrophospora and description of Kuklospora and Intraspora, two new genera in the arbuscular mycorrhizal Glomeromycota. Journal of Applied Botany and Food Quality, Göttingen, v. 80, p. 69-81, 2006.

SILVA, C. F. Manual de análises químicas de Solos, plantas e fertilizantes. 2 ed. Brasília DF: Embrapa, p. $243-$ $627,2009$.

SMITH, S.E; READ, D. J. Mycorrhizal symbiosis. $3^{\mathrm{a}}$ Ed. California: Academic Press, 2008, 800 p.

SOARES A. C. F. et al. Fungos micorrízicos arbusculares no crescimento e nutrição de mudas de jenipapeiro. Revista Ciência Agronômica, Fortaleza, v. 43, p. 47-54, 2012.

SOUZA, G. S. et al. Crescimento, produção de biomassa e aspectos fisiológicos de plantas de Mentha piperita L. cultivadas sob diferentes doses de fósforo e malhas coloridas. Global Science And Technology, Rio Verde, v.
6 , p. $35-44,2013$

TAIZ, L.; ZEIGER, E. Fisiologia vegetal. 5. ed. Porto Alegre: Artmed, 2013. 954 p.

URCOVICHE, R. C. et al. Plant growth and essential oil content of Mentha crispa inoculated with arbuscular mycorrhizal fungi under different levels of phosphorus. Industrial Crops and Products, Amsterdam, v. 67, p. 103107,2015 . 